\title{
Determination of load transfer in reinforced concrete solid slabs by finite element computer analysis
}

\author{
Mohanad Y. Abdulwahid ${ }^{1}$, Imad A. Al-Qasem², Ibrahim Arman ${ }^{3}$ \\ ${ }^{I}$ Department of civil engineering, Koya University, Kurdistan region, Iraq \\ ${ }^{2,3}$ Department of Civil Engineering, Al-Najah National University, Nablus, Palestine
}

\begin{abstract}
According to the ACI building code, the concrete slab can be divided into two types depending on the ratio of the long side to the short side. Regarding the results of the ratio, the concrete slab can be divided as one-way and two-way slabs. The main objective of this paper is to study the stress or moments distribution in solid slab panel in its two directions and compare with ACI code assumption that the load is transferred mainly in short direction and most of the load is transferred in one direction only if the ratio of the longer span to the shorter span is greater than one. This will be discussed by analyzing one panel of solid slab using the computer software SAP2000. Two types of panels will be used; the first one a panel that is supported simply on its four sides and the second panel is supported only by four pin supports and beams. This paper shows that the gravity load on the slab is transferred to long and short direction. This means that one-way concrete solid slab doesn't exist and all concrete solid slabs work as a two-way concrete slab.
\end{abstract}

Keywords: bending stress, FEM analysis, one-way slab, simply supported slab, two-way slab

\section{Introduction}

Reinforced concrete structures make up of a set of elements that interact together as a one unit to carry the dead loads and live loads placed on the structure safely. Most reinforced concrete structures are subdivided into beams and slabs, which are subjected primarily to flexure (bending), and columns, which are subjected to axial compression and bending [1]. A good design requires accurate calculation of loads on structure to get the requirements of any design which are safety and economy. A slab is a structural element and has little thickness comparing to its cross section. Slabs are widely used in floor and roof construction. A concrete slab surrounding beams on all four sides work as one-way slab or two-way slabs depending on the dimensions of concrete slab. If the ratio of the long dimension to the short dimension of a slab panel is greater than or equal to 2.0, most of the load on the slab is transferred to the long pair of beams that is, the load path is along the short dimension of the slab panel. The load path along the long dimension of the slab is negligible. If the ratio of the long to short dimension of a slab panel is less than 2.0, the slab is considered to behave as a two-way slab. In a two-way slab, both directions participate in carrying the load [2]. This is in general what is common in reinforced concrete design of slabs.

The use of computer program like SAP2000 for analysis and design is widely concerned with by civil engineers. SAP2000 software is one of little available computer software that is user-friendly. In SAP2000 software, it is easy to model any structural shape and to generate element meshing. Also, it is easy to edit or view any data using spread sheets and it has automatic sections and section properties [3]. Once, with the appearance of powerful computers and software based on finite element method, can achieve a threedimensional analysis of structural models with large number of bays and levels. The structural analysis based on F.E.M. has a high level of accuracy and structural detailing. Thus, this calculation method can be considered as an exact method [4].

Some researchers have investigated the analysis of slabs spanning in two directions under concentrated load an alternative approximate method for determining the bending moments of the slab under study in the two directions is investigated in on the elastic analysis [5].

Other researches have studied the ultimate load of the reinforced concrete slabs using the finite element method and mathematical programming [6]. This paper discusses two results related to maximum bending stresses created in concrete solid slab by focusing, firstly, on the significant differences between the results of modeling by SAP2000 and the ACI building code method, and secondly, on the behavior of concrete solid slab with different dimensions.

This study will represent two types of one panel solid slabs; the first one is a slab with fully edge pin supports and the second is a slab with corner pin supports and edge beams. By using slab type 1, load distribution in two directions will be discussed and the stresses will be determined. The load in this slab is transferred in two directions depending on the ratio of the longer span to the shorter span. These stresses will be compared with the maximum stress in one way slab which is determined from the maximum moment for simply supported beam. 
Slab type 2 will be used in discussion of the difference between edge supported panel and beams supported panel. Also, the stresses in each direction will be determined and compared with each other.

\section{Model Description}

A model represents concrete solid slab is analyzed by using Finite Element Model (F.E.M) in SAP2000. The slab plan is shown in Figure 1. The short side of the panel is denoted by a, and the longer side is denoted by $b$. In order to model the concrete solid slab the following assumptions are used:

1- Each model consists of a concrete solid slab with $150 \mathrm{~mm}$ thickness.

2- The own weight of structure is neglected.

3- The modulus of elasticity of concrete, $\mathrm{E}=25 * 10^{6} \mathrm{kN} / \mathrm{m}^{2}$.

4- The Poisson's ratio of concrete, $v=0.2$

5- The load on the slab is $10 \mathrm{kN} / \mathrm{m}^{2}$

6- Slab type one is a slab with pin supports at the four sides

7- Slab type two is a slab with four corner pin supports and four edge beams

8- In slab type 2, the perimeter beams that are supported on corner pin supports are: $250 \times 250,250 \times 400$, $250 \times 600,250 \times 800,250 \times 1250,250 \times 1500,250 \times 2000$ and 250x2500mm

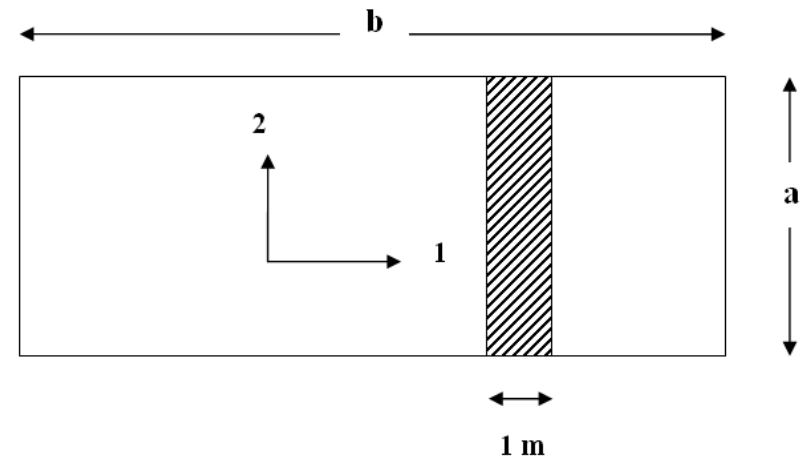

Fig.1. Plan of concrete slab

The short side of the panel is assumed to be $4 \mathrm{~m}$ and the long side is varied. The long side, $\mathrm{b}=4,6,8$, 12,16 , and $20 \mathrm{~m}$. This gives a panel ratio of $1,1.5,2,3,4$ and 5 .

The maximum moment in the slab in the short direction, $a=4 \mathrm{~m}$ is:

$$
M=\frac{w \times a^{2}}{8}=\frac{10 \times 4^{2}}{8}=20 \mathrm{kN} . \mathrm{m}
$$

The maximum stress in short direction (in direction $2\left(\mathrm{~S}_{22}\right)$ in sap2000 model) is:

$$
S_{22}=\frac{6 \times M}{b \times h^{2}}=\frac{6 \times 20}{1 \times 0.15^{2}}=5333 \mathrm{kN} / \mathrm{m}^{2}(5.333 \mathrm{MPa})
$$

So, the maximum stress in slab in short direction; if it works as fully one way slab; is $5.333 \mathrm{MPa}$ and the stress in the other direction (long direction) is very small comparing with this value.

\section{Results AND Discussion}

The computer software SAP2000 is used to model the different slabs. Figure 2 shows the structural model for slabs with edge pin supports and Figure 3 shows the structural model for slabs with beams.

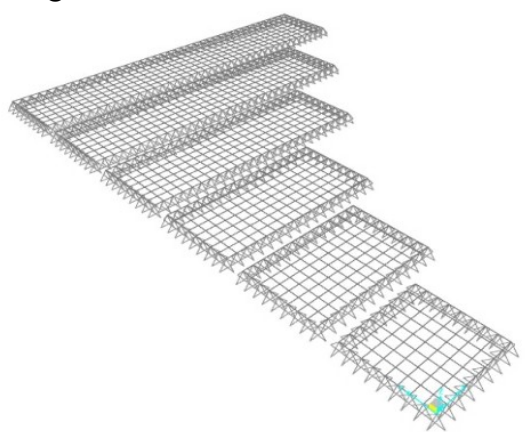

Fig.2.SAP2000 structural model for slabs with edge pin supports 


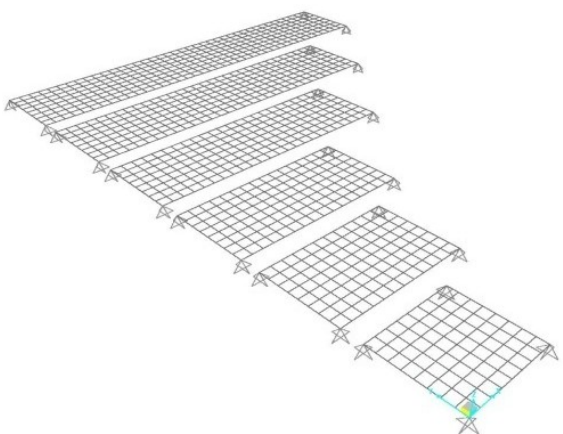

Fig.3.SAP2000 structural model for slabs with edge beams

\subsection{Analysis for Slab with Edge Pin Support}

For slab type 1, the structural analysis of the slab models shows that the stresses in the long direction are smaller than the stresses in the short direction. This emphasizes the common knowledge that larger loads are transferred in the shorter direction in slabs. This result is obtained for slabs with edge supports not edge beams. Figure 4 shows the moments in slab with edge supports in short direction. The maximum stress in the short direction of slab increases as the panel aspect ratio increases. The results are shown in Tables 1 and 2.
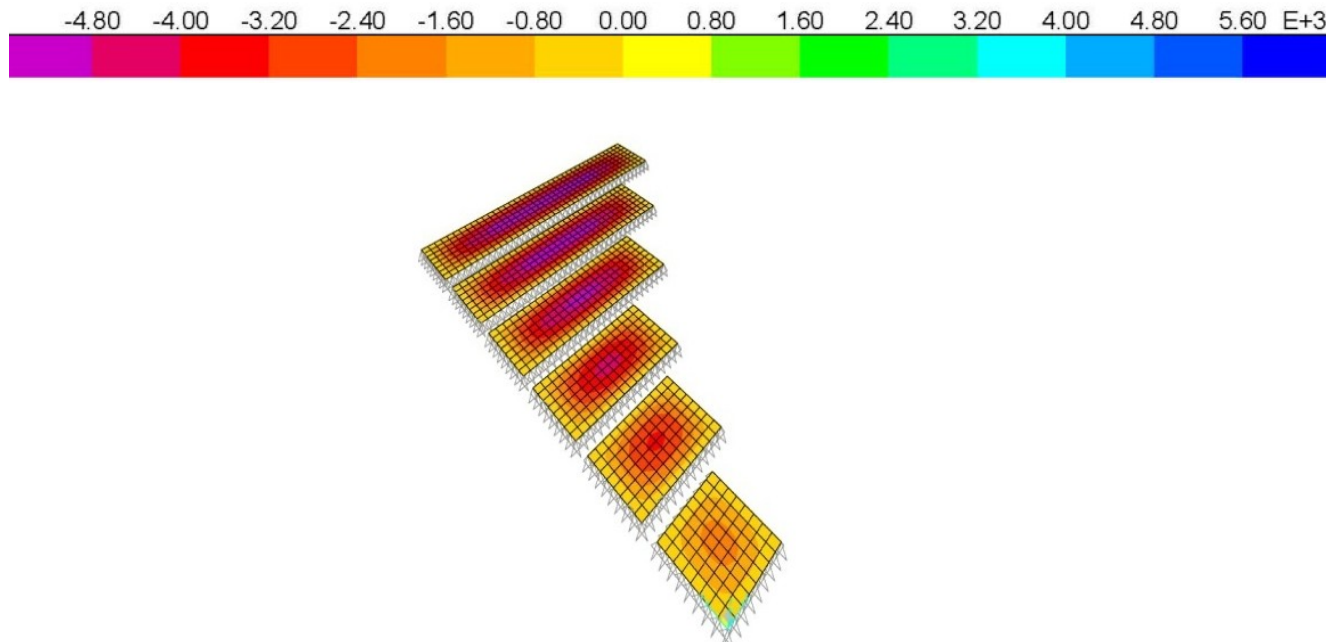

Fig.4.stresses in short direction for slabs with edge supports

Table 1: Comparison of maximum stresses by SAP2000 program in short direction and the maximum stress for slabs with pin edge supports by ACI building code

\begin{tabular}{|c|c|c|c|c|c|c|}
\hline Length of long direction $\mathrm{b}$ in $\mathrm{m}$ & 4 & 6 & 8 & 12 & 16 & 20 \\
\hline Panel aspect ratio (b/a) & 1 & 1.5 & 2 & 3 & 4 & 5 \\
\hline $\begin{array}{c}\text { Maximum stress (for short } \\
\text { direction simple span), MPa }\end{array}$ & 5.333 & 5.333 & 5.333 & 5.333 & 5.333 & 5.333 \\
\hline $\begin{array}{c}\text { Maximum stress at mid span in } \\
\text { short direction (S22 in } \\
\text { SAP2000), MPa }\end{array}$ & 1.905 & 3.371 & 4.287 & 5.058 & 5.265 & 5.317 \\
\hline $\begin{array}{c}\text { Difference \% }=((5333-\mathrm{S} 22) / \\
\text { S22)* } 100 \%\end{array}$ & 179.9 & 58.2 & 24.4 & 5.4 & 1.3 & 0.3 \\
\hline
\end{tabular}

Table 2: Comparison of maximum stresses by SAP2000 program in short and long directions slabs with pin edge

\begin{tabular}{|c|c|c|c|c|c|c|}
\hline \multicolumn{2}{|c|}{ supports } \\
\hline Length of long direction b in $\mathrm{m}$ & 4 & 6 & 8 & 12 & 16 & 20 \\
\hline Panel aspect ratio (b/a) & 1 & 1.5 & 2 & 3 & 4 & 5 \\
\hline $\begin{array}{c}\text { Maximum stress at mid span in } \\
\text { long direction (S11 in SAP2000), } \\
\text { MPa }\end{array}$ & 1.905 & 1.817 & 1.635 & 1.566 & 1.561 & 1.561 \\
\hline $\begin{array}{c}\text { Maximum stress at mid span in } \\
\text { short direction (S22 in SAP2000), } \\
\text { MPa }\end{array}$ & 1.905 & 3.371 & 4.287 & 5.058 & 5.265 & 5.317 \\
\hline (S11/S22)*100\% & 100.0 & 53.9 & 38.1 & 31.0 & 29.6 & 29.4 \\
\hline
\end{tabular}


The results of tables 1 and 2 are represrented by graphs as shown in Figures 5 and 6 . The common knowledge that slabs with aspect ratio larger than 2 can be considered as one way slab is not fully correct. The maximum stress in the short direction for this aspect ratio is $4.278 \mathrm{MPa}$ while the target stress is 5.333 . this value represents $80 \%$ of the maximum stress, while the stress in the long direction is 1.635 which Represents $31 \%$ of the maximum stress. It means that large stresses exist in the long direction inspite of that the panel aspect ratiois larger than 2.

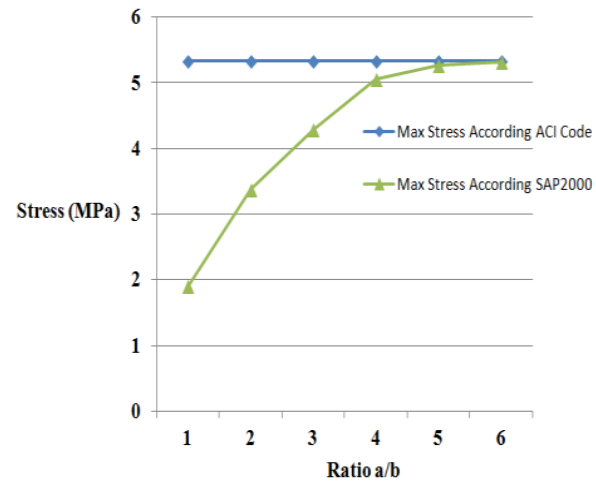

Fig.5. Comparison of maximum stresses on the pin edge supports concrete solid slab by SAP2000 program and the maximum stress for simple span in short direction

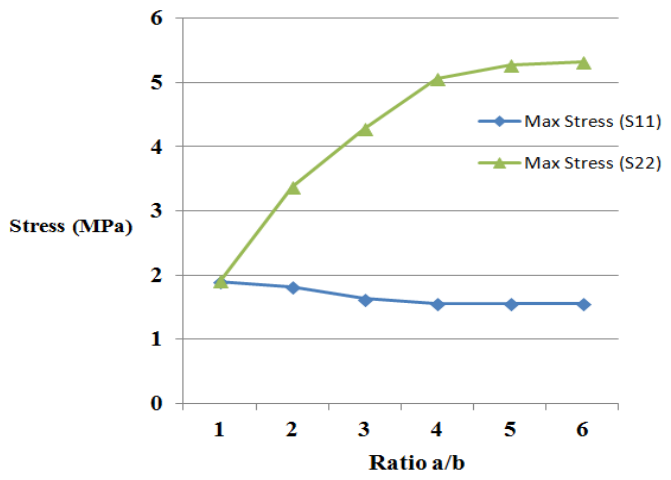

Fig. 6. Comparison of maximum stresses on the pin edge supports concrete solid slab by using SAP2000 program in long and short directions

\subsection{Analysis for Slab with Corner Supports and Beams}

For slab type 2; slab with corner supports and beams, the load distribution is depending on the beam sizes. Figures 6 and 7 shows the stresses in short and long directions for the case of having very stiff edge beams and figures 8 and 9 shows the stresses in short and long directions for the case of having intermediate beams of size $250 \mathrm{~mm} \times 600 \mathrm{~mm}$. It is noticed that the maximum stress in short direction becomes closer to the value of 5.333MPa if having very stiff beams and the panel aspect ratio is high.

In general there are stresses in short and long directions and the stresses in short directions are larger than the stresses in long directions if there are very stiff beams and the aspect ratio of the panel is greater than one. As the beams stiffness increases the stresses in short directions increases and the stresses in long direction decreases and so for the panel aspect ratio.

The stresses in the long direction in a panel without beams and supported by corner pin supports (columns) are larger than in the small direction. This means that the value of the stress depends on the span only; as the span increases the stress will increase. And as the stiffness of the edge beams increase, the stresses in the slab in long direction decreases and the situation will be closer to the case of slab of edge supports. 


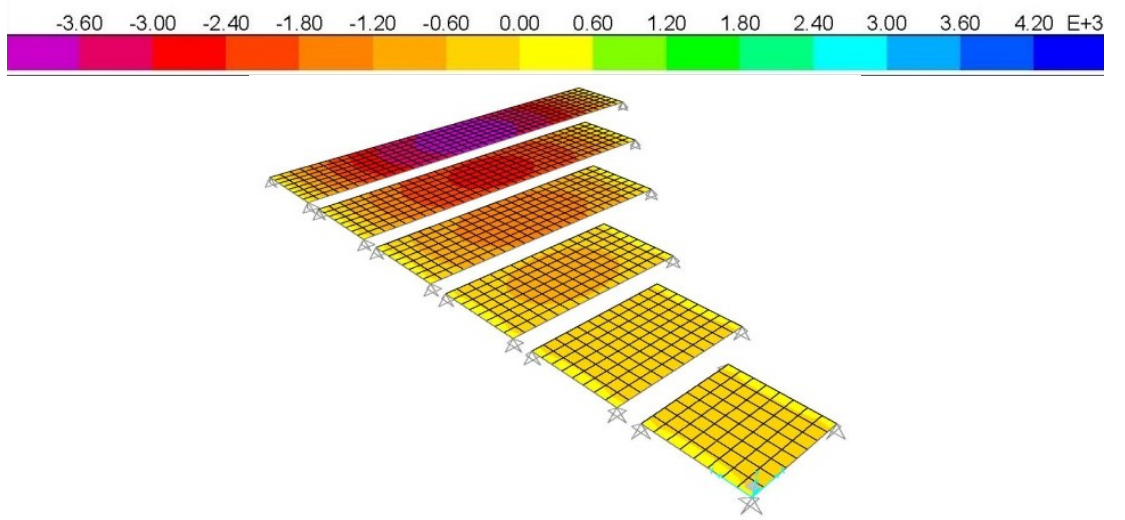

Fig.7. stresses in short direction for slabs with corner supports and beams (very stiff beams, 250x2500mm)

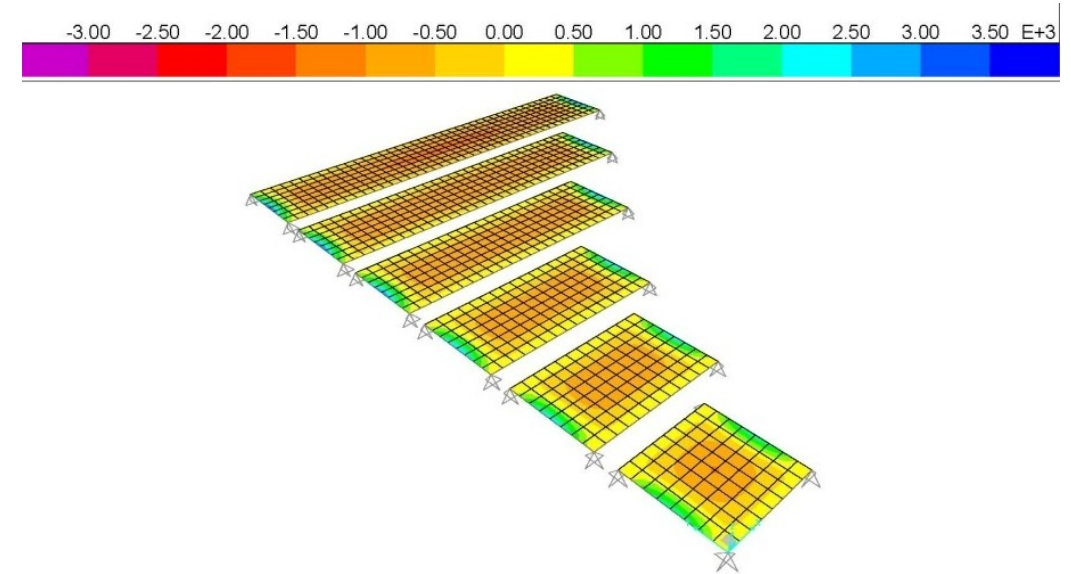

Fig.8. stresses in long direction for slabs with corner supports and beams (very stiff beams, 250x2500mm)

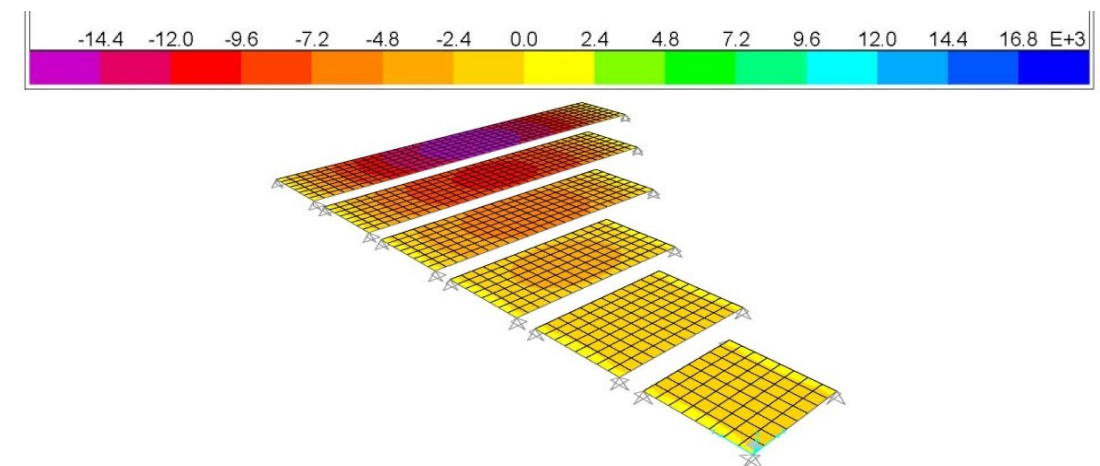

Fig.9. stresses in long direction for slabs with corner supports and beams (intermediate beams, 250x600mm)

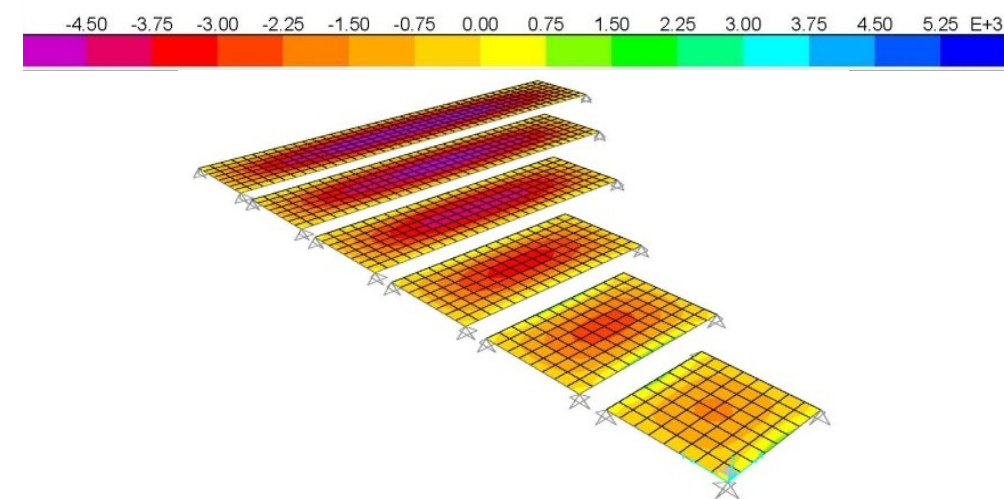

Fig.10. stresses in short direction for slabs with corner supports and beams (intermediate beams, 250x600mm) 
The stress distribution and variation in long and short directions in the slabs with different beam sizes are shown in figures 11,12 and 13 .

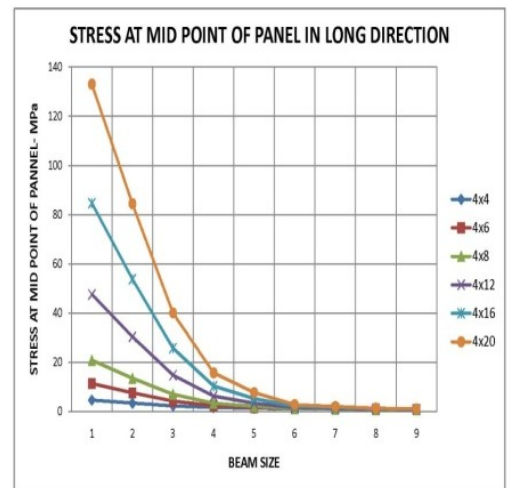

Fig.11.variation of stress values in long direction with panel aspect ratio and beam size

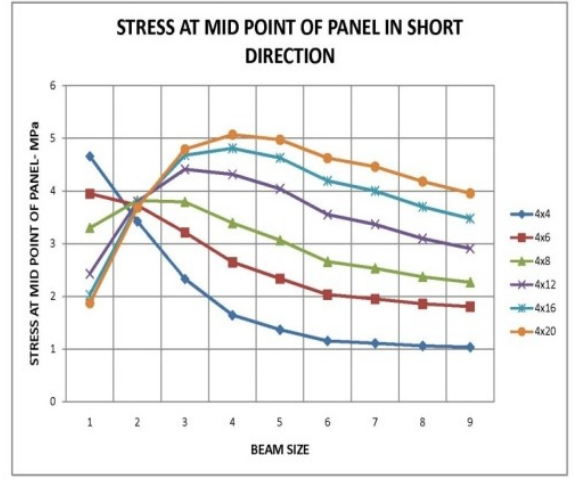

Fig.12.variation of stress values in long direction with panel aspect ratio and beam size

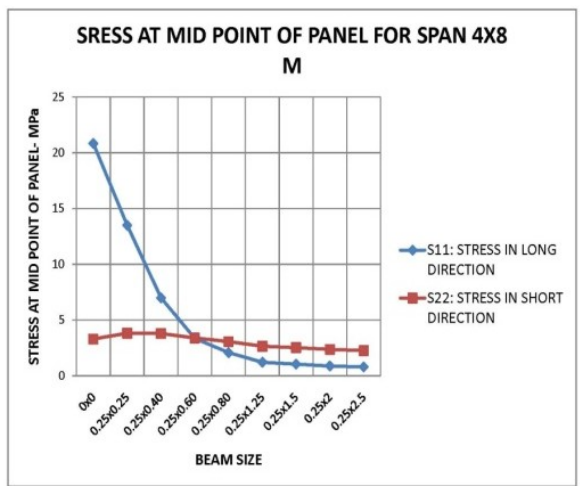

Fig.13.variation of stresses in long and short directions with beam size for panel aspect ratio of 2

\section{Conclusion}

According to the analysis of the data obtained under different dimensions of simply supported concrete solid slab panel, the following points can be concluded:

i. The maximum stress in the slab in the short direction will be closer to that for a simple span (moment equals $\mathrm{wL}^{2} / 8$ ) if the slab has edge supports and has very high aspect ratio not less than 2 to have at least $80 \%$ of maximum stress

ii. The stresses (moments) in long direction are greater than the stresses in short direction for slab without beams or for slab with not very stiff beams

iii. The stresses (moments) in the slab in short direction are larger than the stresses in long direction for slab with very stiff beams

iv. The stresses (moments) in the slab in short direction increases as the stiffness of the supporting beams increases

v. All concrete solid slabs work as two-way concrete slab because the loads are transferred in two directions at any dimensions and the slab has considered values of stresses in any direction. 


\section{References}

[1] Wight and Macgregor. (2012), Reinforced Concrete Mechanics and Design (6 $6^{\text {th }}$ edition)

[2] Mehta, Scarborough, and Armpriest. (2009), Building Construction Principles, Materials, and Systems

[3] Jawad.(2012),"Investigation of load distribution factors for simply-supported composite multiple box girder bridges",Master of Applied Science in Civil Engineering, Ryerson University,Toronto, Ontario, Canada

[4] Parv and Nicoreac. (2012) "Global structural analysis of central cores supported tall buildings compared with FEM', Acta Technica Napocensis: Civil Engineering \& Architecture, Vol. 55, No. 3, 252-262

[5] Salama. (2012)," Analysis of slabs spanning in two directions under concentrated load" Housing and Building National Research Center, $1-5$

[6] Alverne.(2012), "Determination of the reinforced concrete slabs ultimate load using finite element method and mathematical programming" .lajss,69-93 